\title{
Tiang Pondasi Beton Bertulang Bambu Versus Kayu Mahang yang digunakan di Tanah Gambut
}

\author{
Aidil Abrar \\ 1)Program Studi Teknik Sipil, Sekolah Tinggi Teknologi Dumai \\ Jl. Utama Karya Bukit Batrem II \\ Email: aidil.abrarce@gmail.com
}

\begin{abstract}
ABSTRAK
Upaya untuk menambah kerapatan tanah gambut salah satunya adalah dengan menggunakan tiang pancang cerucuk kayu.Pondasi cerucuk kayu digunakan untuk meneruskan beban bangunan yang terletak di atas air atau tanah lunak, sehingga pondasi bangunan mampu memberikan dukungan yang cukup untuk mendukung beban tersebut oleh gesekan dinding tiang dengan tanah sekitar, dan untuk mendukung pondasi bangunan yang permukaan tanahnya mudah tergerus air.Untuk menggantikan kontribusi pengunaan kayu mahang yang semakin hari susah didapat maka beton bertulang bambu sebagai pengganti kayu mahang yang dapat menjadi pilihan untuk diaplikasikan pada pondasi cerucuk rumah sederhana, yang kemudian hari dapat sebagai alternatif pada masyarakat khususnya di kota Dumai.Penelitian ini dengan melakukan eksperimen dengan membuat sejumlah benda uji dalam bentuk tiang beton bertulang bambu dengan ukuran $\phi 10 \mathrm{~cm}$ dengan bentang $300 \mathrm{~cm}$. Tiang beton bertulang bambu yang diuji ditumpu dengan tumpuan sederhana.Dengan pengujian tiang beton bertulang bambu pada jarak 1/3 dari bentang tiang beton bertulan. Proporsi campuran yang digunakan adalah perbandingan berat yang setara dengan perbandingan volume dengan beton K175.Dari hasil penelitian yang membuat alternatif untuk menambah daya dukung tanah di tanah gambut ini, bisa dipakai sebagai alternatif pengganti kayu mahang yang sulit didapatkan, serta menjaga ekosistim alam tanpa menebang kayu mahang sebagai sumber oksigen di daerah gambut.
\end{abstract}

Kata kunci: pondasi, tanah gambut, cerucuk kayu

\begin{abstract}
Efforts to increase the density of the peat soil one of them is to use a wood pile. The foundation used to carry the load of the building which is located on the water or soft ground, so that the building foundation is able to provide sufficient support to support the load by friction with the ground around the pole wall, and to support building foundations easily eroded soil surface water.To replace the contribution of the use of "Kayu Mahang" which is increasingly hard to come by bamboo reinforced concrete instead of Kayu Mahang that can be applied to the foundation of choice for pile foundation at house, which later can be as an alternative to the peoples, especially in the city of Dumai. This research by conducting experiments with making a number of test specimens in the form of reinforced concrete poles of bamboo with a size $10 \mathrm{~cm}$ and $300 \mathrm{~cm}$ span. Bamboo poles reinforced concrete tested with footstool simplebeam testing, bamboo reinforced concrete pole at a distance of 1/3 span. The proportion of the mixture used is the ratio of weight equivalent to volume ratio with concrete $K$ 175.From the research that makes alternatives to increase the carrying capacity of the
\end{abstract}


soil in the peat soil, can be used as an alternative to Kayu Mahang difficult to obtain, and keepnatural ecosystems as a source of oxygen..

Keywords: foundation, peat soil, wood foundation.

\section{Pendahuluan}

Provinsi Riau merupakan salah satu provinsi di Indonesia yang sebagian besar tanahnya lunak meliputi tanah gambut, tanah lempung, dan tanah lanau. Tanah gambut merupakan jenis tanah yang memiliki daya dukung rendah sehingga akan menghadapi masalah apabila tanah gambut menerima beban yang cukup besar.

Upaya untuk menambah kerapatan tanah gambut salah satunya adalah dengan menggunakan tiang pancang cerucuk kayu. Pondasi cerucuk kayu digunakan untuk meneruskan beban bangunan yang terletak di atas air atau tanah lunak, sehingga pondasi bangunan mampu memberikan dukungan yang cukup untuk mendukung beban tersebut oleh gesekan dinding tiang dengan tanah sekitar, dan untuk mendukung pondasi bangunan yang permukaan tanahnya mudah tergerus air.

Penelitian ini adalah menggunakan beton tiang bertulangan bambu sebagai pondasi cerucuk sebagai pengganti kayu mahang yang sekarang ini sangat susah didapat, pertumbuhan kayu mahang sangat lama berkisar $7-8$ tahun sedangkan bambu pertumbuhan hanya sekitar $3-5$ tahun sudah dapat digunakan. Beton bertulang bambu telah menjadi inovasi sejak tahun 1990an. Menurut Khare (2005) balok bertulang bambu sangat disarankan untuk daerah yang terbatas dalam ketersediaan tulangan baja polos. Menurut penyidikan yang telah dilakukan, kekuatan tegangan tarik ultimit dari bambu sekitar $1000-2000 \mathrm{~kg} / \mathrm{cm} 2$ dimana nilai tersebut merupakan $1 / 2$ sampai $1 / 4$ dari tegangan tarik ultimit besi (Surjokusumo dan Nugroho, 1993), sehingga sangat menarik untuk direncanakan peningkatan potensi bambu sebagai material pengganti besi agar dapat mengurangi biaya pembuatan beton bertulang baja.

Untuk menggantikan kontribusi pengunaan kayu mahang yang semakin hari susah didapat . beton bertulang bambu sebagai pengganti kayu mahang yang dapat menjadi pilihan untuk diaplikasikan pada pondasi cerucuk rumah sederhana, yang kemudian hari dapat sebagai alternatif pada masyarakat khususnya di kota Dumai.

Perumusan masalah adalah untuk mengetahui potensi tiang beton bertulang bambu dengan penggunaan kayu mahang dan sebagai alternatif pengganti penggunaan kayu mahang dan untuk mengetahui kekuatan lenturan tiang beton bertulang bambu berdasarkan jenis bambu dan susunanya.

Beton yang digunakan adalah beton K-175.Pengujian tiang beton bertulang bambu dilakukan pada umur beton 28 hari.Diameter tiang beton bertulang bambu adalah $10 \mathrm{~cm}$ dengan bentang $3 \mathrm{~m}$.Pengujian dilakukan dengan pembebanan yang diberikan $1 / 3$ dari bentang tiang beton bertulang bambu.Jumlah sampel 4 buah dengan 2 bambu utuh dan 2 yang dibelah atau diserut 
Diameter tulangan bambu utuh 1,5-2 cm dan bambu yang dibelah dengan ukuran 1 $-1,5 \mathrm{~cm}$. Penelitian yang sudah dilakukan memakai tulangan bambu sebagai balok, antara lain : "Analisa balok beton bertulang bambu profil dengan Variasi Susunan Tulangan" (Institut Pertanian Bogor 2013). Dan "Kapasitas Lentur Plat Beton Bertulangan bambu" (Universitas Udayana Denpasar 2007).

\section{Tiang Pancang Kayu}

Pemakaian tiang pancang kayu adalah cara tertua dalam penggunaan tiang pancang kayu sebagai pondasi. Tiang pancang kayu dibuat dari batang pohon dan biasanya diberi bahan pengawet. Pada pemakaian tiang pancang kayu tidak diizinkan untuk menahan beban lebih tinggi dari 25 sampai 30 ton untuk setiap tiang. Tiang kayu akan tahan lama apabila tiang kayu tersebut dalam keadan selalu terendam penuh di bawah muka air tanah dan akan lebih cepat busuk jika dalam keadaan kering dan basah yang selalu berganti -ganti. Tiang pancang kayu tidak tahan terhadap benda -benda agresif dan jamur yang bisa menyebabkan pembusukan.

Keuntungan pemakaian tiang pancang kayu :

1. Tiang pancang kayu relatif ringan sehingga mudah dalam pengangkutan.

2. Kekuatan tariknya besar sehingga pada waktu diangkat untuk pemancangan tidak menimbulkan kesulitan seperti pada tiang pancang beton precast;

3. Mudah untuk pemotongannya apabila tiang kayu sudah tidak dapat masuk lagi ke dalam tanah

4. Tiang pancang kayu lebih sesuai untuk friction pile dari pada end bearing pile karena tekanannya relative kecil.

Kerugian pemakaian tiang pancang kayu :

1. Karena tiang pancang kayu harus selalu terletak di bawah muka air tanah yang terendah agar dapat tahan lama, maka jika letak air tanah terendah tersebut sangat dalam, hal ini akan menambah biaya untuk penggalian;

2. Tiang pancang kayu mempunyai umur relatif kecil dibandingkan dengan tiang pancang baja atau beton, terutama pada daerah yang tinggi air tanahnya sering naik turun.

3. Pada waktu pemancangan pada tanah yang berbatu ujung tiang pancang kayu ini bisa rusak atau remuk.
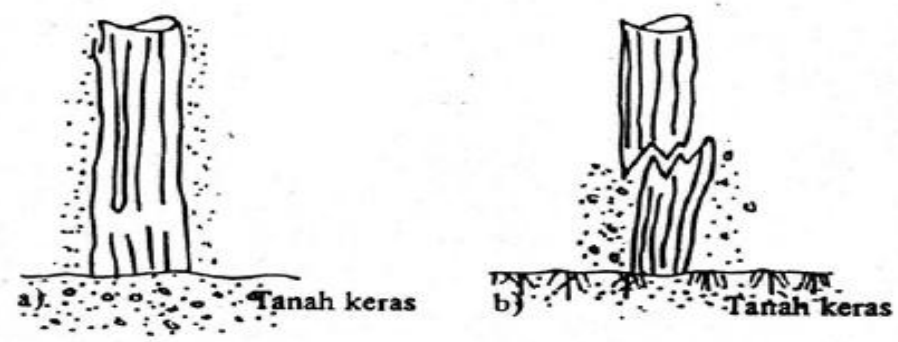

Gambar1. Tiang pancang kayu

Sumber: Bowles, J (1991) 
Tiang Pancang Beton

\section{a. Precast reinforced concrete pile}

Precast reinforced concrete pile adalah tiang pancang dari beton bertulang yang dicetak dan dicor dalam acuan beton (bekisting), kemudian setelah cukup kuat atau keras lalu diangkat dan dipancangkan.Tiang pancang beton ini dapat memikul beban lebih besar dari 50 ton untuk setiap tiang, tetapi tergantung pada dimensinya. Penampang precast reinforced concrete pile dapat berupa lingkaran, segi empat dan segi delapan.

Keuntungan pemakaian precast reinforced concrete pile yaitu:

1. Precast reinforced concrete pile mempunyai tegangan tekan yang besar tergantung pada mutu beton yang digunakan;

2. Dapat diperhitungkan baik sebagai end bearing pile ataupun friction pile

3. Tahan lama dan tahan terhadap pengaruh air ataupun bahan - bahan korosif asal beton dekingnya cukup tebal untuk melindungi tulangannya;

4. Karena tidak berpengaruh oleh muka air tanah maka tidak memerlukan galian tanah yang banyak untuk poernya.

Kerugian pemakaian precast reinforced concrete pile:

1. Karena berat sendirinya besar maka biaya pengangkutannya akan mahal, oleh karena itu precast reinforced concrete pile dibuat di tempat pekerjaan;

2. Tiang pancang beton ini baru dipancang apabila sudah cukup keras hal ini berarti memerlukan waktu yang lama untuk menuggu sampai tiang pancang beton ini bisa digunakan;

3. Bila memerlukan pemotongan, maka pelaksanaannya akan lebih sulit dan membutuhkan waktu yang lebih lama juga;

4. Bila panjang tiang kurang dan karena panjang tiang tergantung pada alat pancang (pile driving) yang tersedia, maka akan sukar untuk penyambungan dan memerlukan alat penyambung khusus;

5. Apabila dipancang di sungai atau di laut tiang akan bekerja sebagai kolom terhadap beban vertical dan dalam hal ini akan ada tekuk sedangkan terhadap beban horizontal akan bekerja sebagai cantilever.
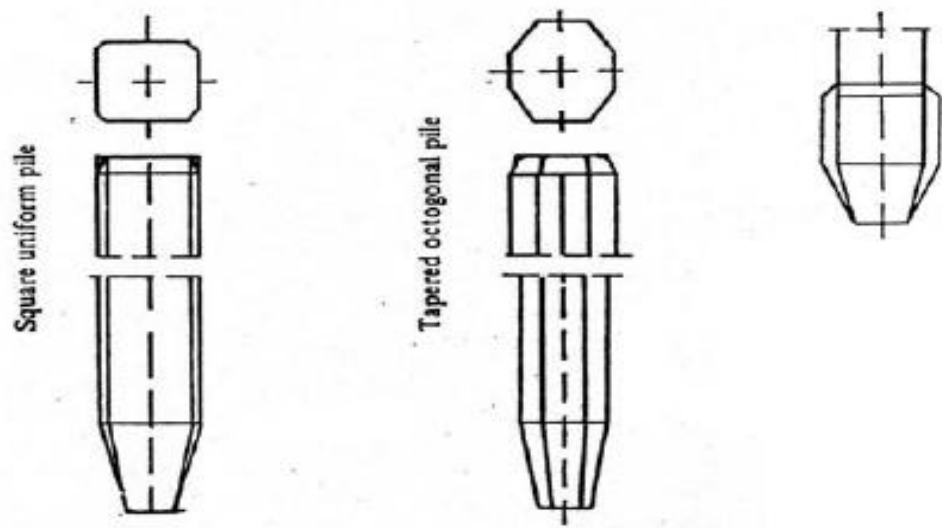

Gambar2. Tiang pancang precast reinforced concrete pile

Sumber: Bowles, J (1991) 


\section{b. Precast Prestressed Concrete Pile}

Precast prestressed concrete pile adalah tiang pancang dari beton prategang yang menggunakan baja dan kabel kawat sebagai gaya prategangnya.

Keuntungan pemakaian precast prestressed concrete pile adalah:

1. Kapasitas beban pondasi yang dipikulnya tinggi;

2. Tiang pancang tahan terhadap karat;

3. Kemungkinan terjadinya pemancangan keras dapat terjadi.

Kerugian pemakaian precast prestressed concrete pile adalah:

1. Sukar ditangani;

2. Biaya pembuatannya mahal;

3. Pergeseran cukup banyak sehingga prategangnya sukar disambung.

\section{c. Cast in place}

Tiang pancang cast in place ini adalah pondasi yang dicetak di tempat pekerjaan dengan terlebih dahulu membuatkan lubang dalam tanah dengan cara mengebor. Pelaksanaan cast in place ini dapat dilakukan dengan dua cara:

1 Dengan pipa baja yang dipancangkan ke dalam tanah, kemudian diisi dengan beton dan ditumbuk sambil pipa baja tersebut ditarik ke atas.

2 Dengan pipa baja yang dipancangkan ke dalam tanah kemudian diisi dengan beton, sedangkan pipa baja tersebut tetap tinggal dalam tanah.

Keuntungan pemakaian cast in place:

1. Pembuatan tiang tidak menghambat pekerjaan;

2. Tiang tidak perlu diangkat, jadi tidak ada resiko kerusakan dalam pengangkutan;

3. Panjang tiang dapat disesuaikan dengan keadaan dilapangan.

Kerugian pemakaian cast in place:

1. Kebanyakan dilindungi oleh hak patent;

2. Pelaksanaannya memerlukan peralatan khusus;

3. Beton dari tiang yang dikerjakan secara cast in place tidak dapat dikontrol.

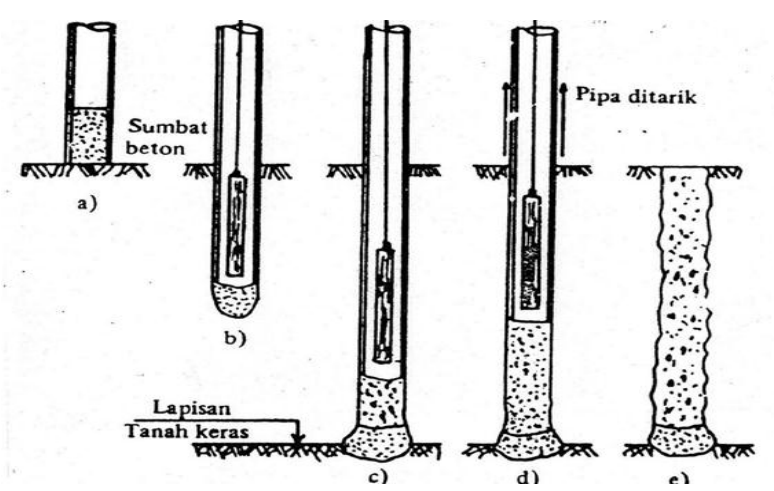

Gambar3. Tiang pancang cast in place

Sumber: Bowles, J (1991) 


\section{MetodePenelitian}

Metode Penelitian adalah metode eksperimen dengan pengambilan sampel dan data dilakukan dengan membuat sejumlah benda uji dalam bentuk tiang beton bertulang bambu dengan ukuran $\theta 10 \mathrm{~cm}$ dengan bentang $3,00 \mathrm{~cm}$. Tiang beton bertulang bambu yang diuji ditumpu dengan tumpuan sederhana.Dengan pengujian tiang beton bertulang bambu pada jarak 1/3 dari bentang tiang beton bertulan. Proporsi campuran yang digunakan adalah perbandingan berat yang setara dengan perbandingan volume dengan beton K-175.Data diperoleh setelah melakukan pengujian kuat tekan beton dan pengujian kelenturan tiang beton bertulang bambu. Bambu yang digunakan adalah bambu yang mudah ditemukan di daerah kota Dumai atau yang biasa disebut dengan bambu pagar, bambu yang digunakan sebagai tulangan ada yang utuh dan bambu yang dibelah atau diserut.

Tipe tulangan tiang beton bertulang bambu ini ada 4 tipe yaitu:

1 tipe 1 bambu yang utuh bertulang 5

2 tipe 2 bambu yang utuh bertulang 4

3 tipe 3 bambu yang dibelah atau diserut bertulang 5

4 tipe 4 bambu yang dibelah atau diserut bertulang 4

\section{Hasil danPembahasan}

Bagian ini merupakan bagian terpenting dari suatu tulisan. Pada bagian ini, penulis memberikan penjelasan dan menganalisa data-data yang ditampilkan dan mengaitkannya dengan teori atau hasil penelitian terdahulu yang telah diungkapkan dalam pendahuluan. Penulis dituntut untuk mencurahkan segala kemampuannya dalam menganalisis dan memabahas hasil, karena bagian ini menunjukkan kualitas penulis itu sendiri.

Setiap hasil yang ditampilkan baik dalam bentuk grafik, kurva, atau tabel harus ada uraian analisa dan pembahasannya. Jangan sampai pembaca justru tidak dapat memahami hasil tersebut karena minimnya analisa atau penjelasan yang dikemukakan oleh penulis.

\begin{tabular}{|c|c|c|c|c|c|}
\hline No. & $\begin{array}{c}\text { Umur } \\
(\text { Hari })\end{array}$ & $\begin{array}{c}\text { Berat } \\
(\text { Gram })\end{array}$ & $\begin{array}{c}\text { Beban } \\
(\mathrm{KN})\end{array}$ & $\begin{array}{c}\text { Kuat } \\
\text { Tekan } \\
(\mathrm{MPa})\end{array}$ & $\begin{array}{c}\text { Kuat } \\
\text { Tekan } \\
\left(\mathrm{kg} / \mathrm{cm}^{2}\right)\end{array}$ \\
\hline 1 & 28 & 7881.5 & 270 & 12.00 & 120 \\
\hline 2 & 28 & 7970 & 360 & 15.99 & 159,9 \\
\hline 3 & 28 & 8033.5 & 400 & 17.77 & 177,7 \\
\hline 4 & 28 & 8059.5 & 420 & 18.66 & 186,6 \\
\hline
\end{tabular}

Tabel 1.Hasil Uji Kuat Tekan Beton

Tabel 1.menyatakan bahwa kuat tekan beton maksimum yaitu pada sample kubus nomor 4 mencapai 18,66 Mpa $\left(186,6 \mathrm{~kg} / \mathrm{cm}^{2}\right)$.Telah memenuhi mutu beton yang diinginkan yaitu $175 \mathrm{~kg} / \mathrm{cm}^{2}$. 

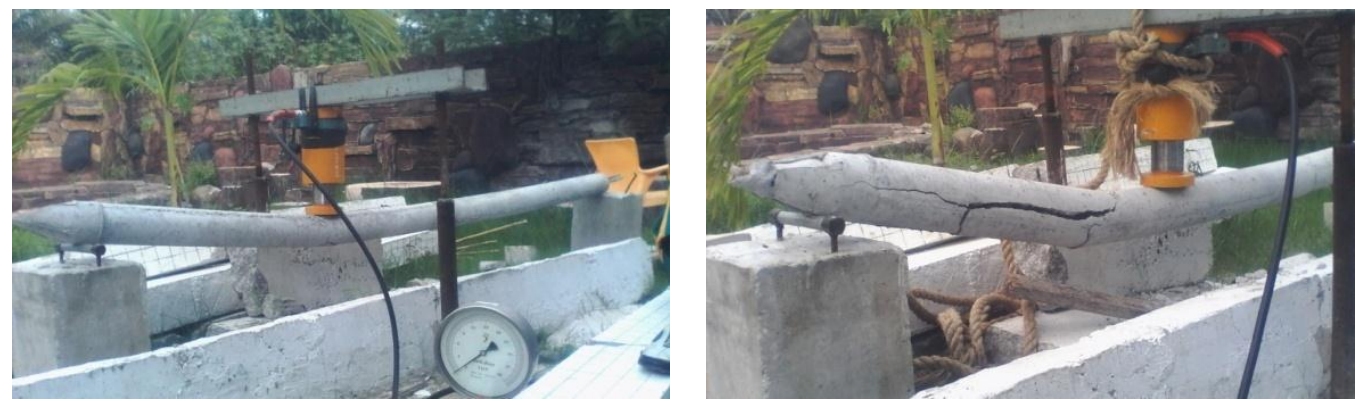

Gambar 4.Pengujian lentur pada tiang bertulangan bambu

Pengujian tiang beton bertulang bambu ini dilakukan untuk mengetahui seberapa besar ketahanan tiang beton betulang bambu mampu menahan beban terpusat yang diletakkan pada posisi $1 / 3$ dari bentang tiang dan membandingkan dengan kayu mahang dan seberapa besar lendutan yang terjadi.Karena keterbatasan alat uji, dilakukanlah seperti pengujian balok, yang aplikasi pada cerocok didalam pondasi mengalami beban gesekan tanah horizontal $1 / 3$ dari bentang tiang.

Tulangan 5 bambu utuh adalah yang terbesar mampu menahan beban dari pengujian, berikut proses pengujian tulangan 5 utuh

1. Hingga beban mencapai $350 \mathrm{~kg}$ benda uji hanya mengalami lendutan

2. Pada saat beban mencapai $400 \mathrm{~kg}$ tiang beton bertulang bambu mengalami retak-retak halus

3. Beban mencapai $450 \mathrm{~kg}$ retak yang semula semakin besar

4. Tiang beton bertulang bambu mengalami patah pada saat beban mencapai $550 \mathrm{~kg}$ pengujian dihentikan

5. Tulangan yang mengalami patah berada diatas sedangakan tulangan yang berada dibawah hanya mengalami lendutan.

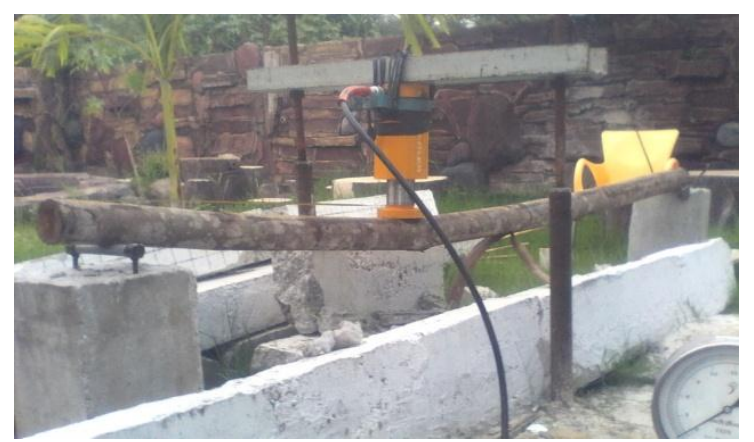

Gambar 5.Pengujian lentur pada kayu mahang

Dari semua benda uji kayu mahang yang mampu menahan beban terbesar yaitu $600 \mathrm{~kg}$, kayu mahang tidak mengalami patah seperti benda uji yang lain hanya mengalami retak-retak halus. Setelah beban mencapai $600 \mathrm{~kg}$ kayu mahang hanya terjadi lendutan saja, setelah itu beban tidak berjalan lagi karena kayu mahang cukup tinggi lendutannya setelah alat uji dilepas kayu mahang kembali seperti semula. 


\begin{tabular}{|c|c|c|c|c|}
\hline \multirow{2}{*}{ No. } & \multirow{2}{*}{ Model } & $\mathrm{H}$ & $\varnothing$ & $\mathrm{P}$ \\
\cline { 3 - 5 } & & $(\mathrm{cm})$ & $(\mathrm{cm})$ & $(\mathrm{kg})$ \\
\hline 1 & T.U. 4 & 300 & 10 & 450 \\
\hline 2 & T.U. 5 & 300 & 10 & 550 \\
\hline 3 & T.S. 4 & 300 & 10 & 500 \\
\hline 4 & T.S. 5 & 300 & 10 & 450 \\
\hline 5 & Kayu Mahang & 300 & 10 & 600 \\
\hline
\end{tabular}

Tabel 2.Hasil Uji lentur beton bertulangan bambu

$\begin{aligned} \text { Keterangan: } & \text { T.U. } \\ \text { T.S. } & =\text { Tulangan Utuh } \\ & \text { Tulangan Serut (belah) }\end{aligned}$

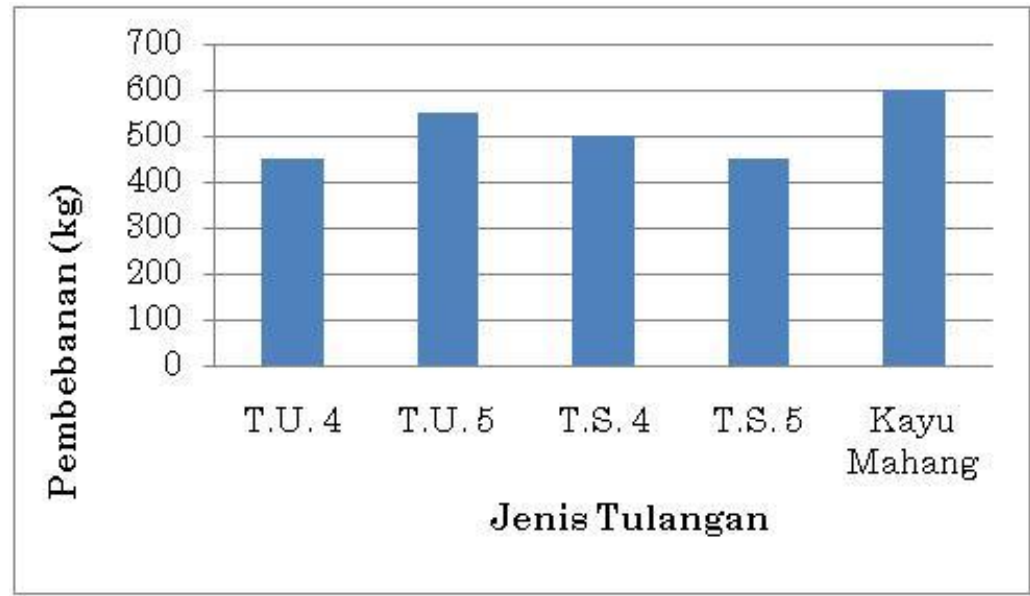

Gambar 6. Gambar grafik pengujian lentur

\section{Simpulan}

Dari hasil penelitian yang membuat alternatif untuk menambah daya dukung tanah di tanah gambut ini, bisa dipakai sebagai alternatif pengganti kayu mahang yang sulit didapatkan, serta menjaga ekosistim alam tanpa menebang kayu mahang sebagai sumber oksigen di daerah gambut.

\section{DaftarPustaka}

1. Bowles, Joseph E, 1992. Analisis dan Desain Pondasi, Jilid 1, Erlangga, Jakarta.

2. Christady H, Hary, 2003. Teknik Fondasi 2, Edisi Kedua, Beta Offset, Yogyakarta.

3. Sardjono HS, 1991. Pondasi Tiang Pancang Jilid 2, Sinar Wijaya, Surabaya, 